\section{Mal praxis en el equipo médico}

\author{
CARLOS PIZARRO ${ }^{1, \mathrm{a}}$
}

\section{Malpractice in health care teams}

To be successful, modern medical acts require the participation of several professionals and assistants and, as such, there has been a steady trend from individual medicine to the collective practice of the profession. This format raises issues in determining when a medical professional or other practitioner is liable for the acts of a colleague. This thesis proposes to resolve the problems involved in the collective practice of medicine by restricting liability to a physician responsible for another practitioner, only to those cases where he/she has been willingly introduced into the medical act.

(Rev Med Chile 2011; 139: 667-671).

Key words: Delivery of health care; Liability, legal; Malpractice.
${ }^{1}$ Facultad de Derecho de la Universidad Diego Portales, Santiago, Chile.

${ }^{a}$ Doctor en Derecho Universidad Paris II (Panthéon-Assas).

Recibido el 16 de diciembre de 2010, aceptado el 5 de abril de 2011

Correspondencia a: Carlos Pizarro República 105, Santiago. Teléfono: (56-2) 6762640 Fax: (56-2) 6762641. E-mail: carlos.pizarro@ udp.cl
$\mathrm{E}$ s frecuente en manuales y artículos de responsabilidad civil referirse a la responsabilidad del "equipo médico"1, indicando que dos teorías serían las idóneas para explicar cómo se resuelve la indemnización de daños ocasionados durante una intervención que involucra la participación de varios médicos y personal adjunto. Se trata de determinar quién o quiénes son los responsables del daño ocasionado en una intervención que requiere una pluralidad de personal médico y asistencial. La primera teoría se le conoce bajo la expresión "capitán del buque", aludiendo a la concentración de la responsabilidad en el médico jefe. La segunda es más amplia, pues responsabiliza a todos quienes participaron en el acto médico consagrando un deber recíproco de vigilancia.

Ambas teorías son insatisfactorias, pues buscan una solución unívoca para la indemnización de perjuicios que se ocasionan en el ejercicio colectivo de la medicina. En lo que sigue se intentará demostrar que para establecer la responsabilidad en casos en que intervienen varios facultativos médicos se requiere definir el tipo de responsabilidad, contractual o extracontractual, el régimen legal, es decir, si se aplica la solidaridad entre los partícipes y que lo esencial para la solución radica en auscultar la voluntad del sujeto para introducir a otro en el cumplimiento de los deberes médicos.

\section{Las teorías sobre la responsabilidad del equipo médico}

Por una parte, se indica que una forma de resolverlo sería concentrar la responsabilidad en el "capitán del buque"; es decir, el médico jefe respondería por todos los otros que intervienen cuando al menos uno de ellos ha cometido un acto culpable y dañino para el paciente. Aquí se concentra la responsabilidad en el médico a cargo de la intervención. Esta teoría implica que cada vez que un dependiente incurre en un acto culpable que origina un daño al paciente, el médico jefe será responsable. Esta teoría no considera que el médico que causó el daño en forma directa puede tener escasa relación con el médico jefe o pudiere ser que se trate de otro médico cuya especialidad impida al médico jefe advertir el acto negligente.

La segunda teoría, y el caso célebre de un ex ministro de la Corte Suprema, conocido como "Caso Beraud", es un excelente ejemplo, expande la responsabilidad, alcanzando a todos los que participaron en la intervención. Todos responden por todos, al extremo que una arsenalera y cualquier miembro del equipo termina siendo condenado a pagar en forma solidaria, exigiéndosele el total de la indemnización, sin importar su real participación en el acto negligente ${ }^{2}$. La solidaridad implica que la víctima una vez reconocida la responsabilidad de más de una persona puede cobrarle el total 
a cualquiera de ellas. Subyace a esta teoría un deber recíproco de vigilancia. Cada miembro del equipo estaría en condiciones de impedir el acto dañino, estableciéndose un deber de advertir al otro que su actividad es incorrecta. Esta forma de analizar el problema deja de lado dos aspectos relevantes. No considera la independencia de las especialidades cada vez más presentes en el ejercicio médico $y$, por otra, no asume las jerarquías que son propias de una intervención médica en que participan varias personas.

La responsabilidad que puede tener lugar a propósito del equipo médico no tiene una lectura jurídica apropiada a través de estas teorías, sino que se hace necesario resolver los daños ocasionados a resultas de una intervención de varios facultativos médicos u otros echando mano a la teoría de la responsabilidad por el hecho ajeno. Esto implica determinar las funciones específicas de los miembros del equipo.

Referirse a la responsabilidad del equipo médico no es correcto, porque este grupo de personas nunca responde como si fuera una persona jurídica o moral específica. La responsabilidad siempre es de naturaleza individual. El equipo médico no es responsable en sí, siendo necesario establecer la responsabilidad de cada miembro que participa en la intervención particular en que un paciente resulta con un daño. Cada sujeto responderá por sí mismo o por los actos de otro si se cumplen las condiciones de responsabilidad respectivas para cada modelo.

Concentrar la responsabilidad sólo en el médico jefe es abusivo, pues puede ocurrir que responda por un daño ocasionado por otro miembro del equipo que ni siquiera está en condiciones de vigilar o que tampoco escogió para acompañarlo en la intervención defectuosa.

Tampoco es acertado que todos respondan por todos, pues no hay buenas razones que justifiquen que una arsenalera o un enfermero subordinado al médico jefe termine pagando la indemnización ocasionada por un acto de este último.

Entonces la pregunta que surge es cómo debe determinarse la responsabilidad cuando interviene un grupo de personas en una operación o acto médico, lo que se conoce usualmente bajo la expresión de responsabilidad del equipo médico o equipo sanitario y si esa responsabilidad corresponde que sea solidaria entre los miembros de dicho grupo.

\section{La responsabilidad contractual y extracontractual}

Una primera cuestión insoslayable en el análisis jurídico de todo problema médico consiste en dilucidar si se aplicarán las reglas de los contratos o aquellas de la responsabilidad extracontractual. Si bien esta distinción para la medicina parece artificiosa y difícil de entender para médicos y pacientes, pues significa aplicar reglas distintas según se trate de un paciente relacionado por un contrato con el médico o no, es cierto que las diferencias entre ambos estatutos, sobre todo a propósito de la medicina, se han ido atenuando. La distinción entre lo contractual y extracontractual está delimitada por la existencia o no de un acuerdo de voluntades previo entre el paciente y el médico o facultativo. Por ejemplo, si el paciente ha sido atendido en la consulta del médico y ahí se origina la decisión de la intervención, no cabe duda que hay un contrato entre el paciente y ese médico. Tambien concurre una relación contractual si el paciente requiere una consulta médica en una Clínica, la cual mantiene un grupo de profesionales médicos a elección del paciente. En este caso el contrato es entre el paciente y la Clínica. Distinto es si el paciente llega inconsciente y de urgencia a la Clínica, pues en esta hipótesis no pudo manifestar voluntad alguna para que se formara el contrato. El contrato médico o de prestación médica es la regla general, mientras que la excepción es la relación extracontractual. La importancia de distinguir si nos encontramos frente a una relación contractual o extracontractual es relevante para saber las reglas que se aplican para solucionar el problema jurídico. Las diferencias usuales atañen a la prueba de la culpa, el ámbito de daños indemnizables y la aplicación de la solidaridad ${ }^{3}$. En materia contractual la culpa se presume si queda acreditada la existencia de la obligación, según prescribe el artículo 1.547 inciso $3^{\circ}$ al declarar que corresponde al deudor probar que fue diligente; en cuanto a los daños indemnizables, tratándose de una relación contractual se restringe al daño previsto, salvo dolo, en cambio, la indemnización por daños extracontractuales comprende los imprevistos. Por último, la solidaridad es una excepción en las relaciones contractuales, lo que se diferencia del ámbito extracontractual.

La forma de entender la responsabilidad que se le imputa a miembros de un equipo médico es a través de la teoría de la responsabilidad por el 
hecho de otro establecida en forma expresa para la responsabilidad civil extracontractual; en cambio, tratándose de responsabilidad contractual no aparece como necesario referirse a la responsabilidad por el hecho de otro, bastando la responsabilidad directa $^{4}$.

Siendo la regla general que concurra un vínculo contractual con el médico o la Clínica que presta servicios terapéuticos más allá de la hotelería y la alimentación, lo normal es que se apliquen las reglas contractuales para resolver los problemas indemnizatorios cuando se produce un daño a resultas de un evento adverso. En efecto, lo usual es que el médico esté obligado a prestar sus servicios en razón de un contrato con el paciente ${ }^{5}$. En cambio, la aplicación del régimen extracontractual queda marginado a hipótesis excepcionales.

En dos situaciones es usual que se recurra al ámbito extracontractual. La primera es opcional y la segunda es obligatoria para el demandante. La primera refiere al caso en que se ha perseguido la responsabilidad penal del médico y es en ese procedimiento que se ejerce la acción civil. Ahí la víctima -el paciente-puede optar entre la responsabilidad contractual o extracontractual, siendo un típico caso de concurrencia de responsabilidad civil. Lo usual en ese procedimiento será que se opte por la vía extracontractual. En cambio, en la segunda hipótesis, es obligatoria la acción extracontractual. Se trata de víctimas distintas al paciente que reclaman una indemnización, pues ellas carecen de un vínculo contractual con el médico. A estas víctimas se les denomina por rebote o repercusión. Por ejemplo, el cónyuge o conviviente o hijos o ascendientes que reclaman indemnización de daño moral o material a resultas del perjuicio ocasionado al paciente -víctima directa-. En este caso la acción es necesariamente extracontractual.

Siendo la regla lo contractual y la excepción lo extracontractual, trataremos de aclarar en ese orden como se aplica la responsabilidad civil en actos en que participan varias personas, ya sea médicos o personal asistente.

\section{Responsabilidad contractual}

Son variadas las situaciones que llevan a un paciente al quirófano desde un punto de vista jurídico. Los caminos en que se van anudando las relaciones jurídicas son múltiples. Un paciente concurre a la consulta del médico y éste le informa la necesidad de realizar una intervención. El paciente concurre a realizarse unos exámenes en una Clínica de su preferencia, siendo un médico del staff que diagnostica la necesidad de realizar la intervención y, con posterioridad, la ejecuta. Una vez que existe la decisión de realizar la intervención debe procederse a formar el "equipo médico", lo que una vez más presenta variadas posibilidades. La Clínica tiene su staff de facultativos, registrados por la misma, el médico sugiere que lo acompañen determinados colegas -el anestesista, por ejemplo-, o lo que es una mera extravagancia jurídica, el paciente podría sugerir algún miembro del equipo. Todo esto conlleva a que varios sujetos participen en la intervención. Es aquí en que se recurre a las teorías del "capitán del buque" o "todos por todos" a que se hizo alusión. Sin embargo, el criterio para determinar si un sujeto responde por otro radica en averiguar si él lo introdujo en el cumplimiento de sus obligaciones. Sólo en el evento que el paciente acredite que el médico o la Clínica sugirió o motivó que un médico u otro miembro participara en la intervención deberá responder por los actos negligentes que pueda cometer. Así, por ejemplo, si para la intervención de histerectomía total la paciente concurrió a la consulta de su médico ginecólogo usual y éste le sugirió realizar la intervención en tal o cual clínica o con uno o más médicos o asistentes determinados, en ese caso su médico deberá responder por los daños ocasionados con culpa de los miembros del equipo que recomendó. El criterio para fijar la responsabilidad no está en la capacidad de vigilancia entre ellos, sino por la decisión voluntaria que para el cumplimiento de las obligaciones un médico introduce a otro en la intervención médica.

Por el contrario, si la paciente concurre a la clínica de salud, siendo ésta la que propone el médico y el equipo, entonces será la clínica la que deberá responder por los daños ocasionados por algún miembro del equipo médico. Todavía puede ocurrir que el médico intervenga con un equipo de la clínica, no pudiendo reprochársele las negligencias ocasionadas por personas que él no introdujo en el acto médico. Esto tiene sólo como excepción la situación en que se presente una negligencia grosera que el médico debió detectar y no lo hizo. Sin embargo, ahí estaríamos frente a una responsabilidad por culpa propia al no vigilar adecuadamente a los otros miembros del equipo. 
Así queda establecido el criterio para que en el ámbito contractual un médico responda por las actuaciones culpables de otro. Esta afirmación es conforme al artículo 1.679 del Código civil, en conformidad al cual en el hecho o culpa del deudor se comprende el hecho o culpa por quienes responde. Esto explica, también, la razón que no sea necesario, en el ámbito contractual, construir una teoría propia de responsabilidad por el hecho de otro, siendo la culpa del deudor de naturaleza directa y principal.

\section{Responsabilidad extracontractual en el equipo médico}

Según dijimos hay ocasiones en que el régimen legal aplicable son las reglas de la responsabilidad extracontractual. Aquí existe una regla especial que se refiere a la responsabilidad por el hecho ajeno que se invoca de manera frecuente en los casos de negligencia médica, sobre todo cuando se persigue la responsabilidad civil ante la jurisdicción penal. Ya sea que la acción indemnizatoria se haya ejercido en el proceso penal por la víctima directa o quienes reclaman la indemnización sean víctimas por rebote. El artículo 2.320 del Código Civil contempla la responsabilidad por el hecho de otro siempre y cuando se acredite un acto $\mathrm{u}$ omisión culpable del dependiente que causa un daño, el vínculo de subordinación entre el dependiente y el que responde por otro, siendo en ese caso aplicable la presunción de culpa contra este último. Es decir, la víctima -el paciente-debe acreditar que una persona que depende de otra le ocasionó un daño con culpa y, probado esto, la ley entiende que el sujeto que lo tiene a cargo fue también culpable, ya sea por haberlo escogido mal o por no haberlo vigilado en forma apropiada. La presunción de culpa puede derrocarse probando que se empleó la diligencia debida. Esta situación puede verificarse en razón que la clínica responderá por funcionarios, médicos u otros miembros del equipo médico o por imputarse responsabilidad al médico que dirige el equipo por actos negligentes de sus miembros. En estas hipótesis debe aplicarse el mismo criterio que para la responsabilidad contractual.

El factor que importará responsabilidad de la clínica o el médico por la actuación de otro debe justificarse en que lo introdujo para la realización de determinadas tareas, ya sea de hotelería, alimentación o genuinos actos médicos. Sólo en el evento que se justifique esta circunstancia podrá configurarse la responsabilidad por el hecho de otro. No basta, en nuestra opinión, un simple registro que autoriza para desempeñarse en un determinado establecimiento sanitario, sino que debe corroborarse la introducción del médico u otro sujeto en el desempeño de la función que originó el daño con negligencia.

\section{La solidaridad en el equipo médico}

Un tema crucial en la responsabilidad civil en general, y para el ámbito médico, radica en resolver si en presencia de dos o más responsables corresponde a la víctima exigir el total de la deuda a cualquiera o, en cambio, sólo podría cobrar por partes a cada uno de los responsables. Un ejemplo puede clarificar el asunto. Si se acredita en un juicio que efectivamente hubo responsabilidad de dos médicos en una intervención, debe clarificarse si la víctima puede cobrarle la indemnización total a cualquiera de ellos o sólo podría exigir el cumplimiento de una parte, por ejemplo la mitad, a cada uno. La solidaridad implica una garantía para el acreedor o víctima en este caso, pues le permite siempre cobrarle el total a cualquiera de los responsables. Este mecanismo legal permite acrecentar las posibilidades de cobro, aún más cuando sólo uno de los responsables tiene un patrimonio significativo. Tratándose de la responsabilidad contractual, la regla general consiste en que no cabe la solidaridad, salvo que se haya establecido por acuerdo de las partes en el contrato, en el testamento o que lo determine la propia ley. En cambio, en la responsabilidad extracontractual, existe una regla específica que consagra la solidaridad cuando hay dos o más responsables. Si la responsabilidad aplicable a la negligencia médica es la extracontractual y se ha determinado dos o más responsables, la víctima podrá cobrarles el total de la deuda a cualquiera. Si el acto negligente ha sido cometido por dos o más personas no hay duda que se aplica la solidaridad del artículo 2.317 del Código civil. Si se trata de la responsabilidad por el hecho de otro, existe discusión sobre la pertinencia de la solidaridad. Si bien concurren dos responsables, sus actos son independientes y no se cumple con la condición 
del artículo 2.317 que sea un mismo hecho. Pero esta opinión que arranca de la literalidad del texto no ha sido considerada por los tribunales, los cuales aplican la solidaridad a la responsabilidad por el hecho ajeno ${ }^{6}$.

La diferencia persiste y perturba el sistema, pues deja a las víctimas en un desequilibrio en cuanto a la garantía para exigir el pago de la indemnización, según se encuentre en una relación contractual o en cambio en aplicación del estatuto extracontractual. Habiendo afirmado que la regla general es la responsabilidad contractual, cabe sostener que la solidaridad está ausente en la mayoría de los casos de responsabilidad médica con dos o más responsables. No podría, en consecuencia, el paciente víctima de la negligencia médica invocar la solidaridad en el ámbito contractual, debiendo reclamar la indemnización en conformidad a la participación en el daño. Si no existiera forma de determinar la cuota de participación en el daño, se dividirá por partes iguales, según el derecho común de las obligaciones. Se trata de un régimen poco satisfactorio, pues genera desequilibrios difíciles de entender para los ciudadanos, provocando una lejanía con la comprensión de la justicia.

\section{Conclusión}

Tanto para la responsabilidad médica por el hecho de otro en el ámbito contractual como aquella extracontractual, debe probarse que el sujeto que responde por otro lo introdujo en el desempeño de sus funciones que ocasionaron el perjuicio incurriendo en culpa. Esta forma de entender la responsabilidad por el hecho de otro permite unificar en un ámbito sensible de la profesión las reglas aplicables para la solución de los problemas asociados a la medicina en equipo. Por el contrario, en cuanto al régimen legal, la diferencia en cuanto a la solidiaridad persiste, lo que genera una desigualdad en el tratamiento de las víctimas que debiera corregirse por vía legislativa.

\section{Referencias}

1. Galán JC. Responsabilidad civil médica. Madrid: Thompson-Civitas, 2007; p. 125.

2. Corte Suprema, 20 de junio de 1996, disponible en Legalpublishing $\mathrm{n}^{\circ}$ identificador 13.931 .

3. Barros E. Tratado de responsabilidad extracontractual. Santiago: Jurídica, 2006; p. 18-22.

4. Pizarro C. La responsabilidad médica por el hecho de otro. RChDP. 2003; 1: 181-205.

5. Mantilla F. El contrato de prestación de servicios médicos en el derecho colombiano En: Colección de estudios de derecho civil en homenaje a la profesora Inés Pardo de Carvallo. Valparaíso: Ediciones Universitarias de Valparaíso 2008; 483-504.

6. Barros E. Tratado de responsabilidad extracontractual. Santiago: Jurídica, 2006; p. 178. 